\title{
Clínica, testemunho e reparação: itinerários possíveis frente ao trauma
}

\section{Clinic, testimony and reparation: possible routes in the face of}

\section{trauma}

Enviado em: 14/01/2018

Aceito em: 14/01/2018

CORSINI, Cristiana ${ }^{1}$

LEVY, Sofia Débora ${ }^{2}$

\begin{abstract}
Resumo:
O presente artigo pretende analisar algumas interfaces entre 0 relato de testemunhas vítimas de governos ditatoriais e a clínica psicológicadiante de situações traumáticas oriundas de crimes de lesa-humanidade, onde tortura e extermínio ocasionam o declínio da experiência e da narrativa pelas consequências desestruturantes do trauma. Essa desestruturação psíquica compromete a transmissão das memórias individuais às gerações posteriores. Por sua vez, a transmissão das memórias é também embarreirada pela censura política, comprometendo a conformação da memória coletiva. Assim, buscaremos compreender a clínica e o testemunho como instrumentos de enfrentamento ao silenciamento e ao esquecimento produzidos pelos órgãos repressores. A experiência do Projeto Clínicas do Testemunho, implementado no Brasil em 2013, norteia as presentes análises frente a um desafio contemporâneo - o de potencializar o testemunho como acontecimento diante do indizível, bem como instrumento de livre expressão política integrante da memória social a partir e para além do ambiente clínico.
\end{abstract}

Palavras-chave: clínica do testemunho; trauma; ditadura.

\section{Abstract}

This article analyzes relations between the testimonies of victims of dictatorial governments, and psychological

\footnotetext{
${ }^{1}$ Psicóloga. Mestranda do Programa de Pós-Graduação emMemória Social da Universidade Federal do Estado do Rio de Janeiro/UNIRIO.

2 Psicóloga. Prof - Orientadora. Pós-Doutoranda do Programa de Pós-Graduação em Memória Social da Universidade Federal do Estado Rio de Janeiro/UNIRIO.
} 
clinics dealing with traumatic situations arising from human rights crimes, where torture and extermination lead to decline in experience and narrative due to the destructive consequences of the trauma. This psychological disruption compromises the transmission of individual memories to later generations. In turn, the transmission of memories is also hindered by barriers stemming from political censorship, compromising the conformation of a collective memory. We intend to understand clinics and individual testimonies as instruments to face silencing and oblivion produced by repressive government entities. The experience of the Clinic of Testimony Project, implemented in Brazil in 2013, guides these analyzes to a contemporary challenge - to enhance testimony as an event against the unspeakable, as well as an instrument of free political expression that integrates social memory from and beyond the clinical setting.

Keywords: clinic of testimony; trauma; dictatorship

\section{Introdução}

Vislumbrar algumas possibilidades narrativas que nos convoque a uma reflexão acerca dos efeitos de um silenciamento histórico, frente a memórias interrompidas por experiências traumáticas de tortura e aniquilamento social, produzidas por agenciamentos de governos ditatoriais, nos coloca em confronto com o indizível e o irrepresentável - tanto para a elaboração das vítimas quanto para a elaboração da memória social da comunidade afetada.

No intuito de fornecer algum suporte ao início de uma discussão de contorno plural e transdisciplinar, consideramos a importância de compreendermos o trauma para além de sua dimensão individual e psicológica estrita. Para tanto, a contribuição de alguns autores, como Ortega Martínez (2011), que redimensionam o trauma para o campo social, diante de situações de crimes de lesa-humanidade, podem ser paradigmáticas para contextualizarmos as fissuras traumáticas dos períodos moderno e contemporâneo em regimes de exceção. 
Diante do exposto, nos perguntamos como se dão as relações e tensionamentos entre memórias e jogos de poder no Brasil contemporâneoem relação à história do período militar instaurado em 1964? Como a clínica psicológica poderá contribuir, a partir dos depoimentos das testemunhas, plenos de expressões fragmentadas e de excessos, em uma conjuntura social e política de desmentido acerca de situações traumáticas, com efeitos transgeracionais? E até que ponto este excesso poderia ser transladadode uma rede ininterrupta de imagens refratárias a uma historicidade, a um regime de verdade, como produtoras, de narrativas de denúncia do trauma advindo de crimes políticos?

\section{Efeitos transgeracionais nasbarbáries de guerra}

Quem encontra ainda pessoas que saibam contar histórias como elas devem ser contadas? Que moribundos dizem hoje palavras tão duráveis que possam ser transmitidas como um anel, de geração a geração? (BENJAMIN,[1933]/1994, p. 114)

Em seu ensaio "Experiência e pobreza", o filósofo Walter Benjamin ([1933]/1994) apresenta algumas considerações sobre o processo de empobrecimento da experiência na modernidade, iniciando sua narração com a parábola de um velho pai moribundo revelando a seus dois filhos a existência de um tesouro enterrado em seus vinhedos. Após o esforço de desenterrar o tesouro e de não encontrá-lo, o ensinamento que o pai deixa aos filhos como legado é sua experiência de vida, onde a riqueza e a felicidade são extraídas do trabalho e do tempo. Benjamin salienta que a importância conferida aos mais velhos se dava pela transmissão da experiência entre as gerações, através de uma tradição compartilhada de forma contínua de pai para filho.

Neste ensaio, o filósofo também evoca possibilidades reativas à ausência da palavra compartilhada como uma espécie de empobrecimento da narrativa, da experiência e dos meios que possibilitam os recursos fundamentais à vida das coletividades, ao relacionar estes fenômenos com a grande barbárie que foi a Primeira Guerra Mundial.

\footnotetext{
$\mathrm{Na}$ época, já se podia notar que os combatentes tinham voltados silenciosos do campo de batalha. Mais pobres em experiências comunicáveis, e não mais ricos. (...) Porque nunca houve experiências mais radicalmente desmoralizadas que a experiência estratégica pela guerra de trincheiras, a experiência econômica pela inflação, a experiência do corpo pela fome, a experiência moral pelos governantes (BENJAMIN,[1933]/1994, p. 114-115).
}

Benjamin retrata, desta forma, uma nova miséria humana forjada pelo 
desenvolvimento da técnica do capitalismo moderno que se sobrepõe às sociedades artesanais. Neste sentido, conclui que "é preferível confessar que essa pobreza de experiência não é mais privada, mas de toda a humanidade. Surge assim uma nova barbárie" (ibidem, p. 115).

Em “O narrador"([1936]/1994), Benjamin retoma a ideia de declínio da experiência à medida que as narrativas das sociedades artesanais são atravessadas por um deslocamento das relações de trabalho exigidas pelo capitalismo moderno, desagregando as experiências de vida e a transmissão oral destas comunidades. Para Benjamin, a arte de narrar estaria implicada a uma forma de organização social précapitalista, com outro referencial de tempo e de trabalho.

Ao relacionar os ensaios "Experiência e pobreza" e "O narrador" de Benjamin, Gagnebin (2011) salienta o perigo de uma leitura desatenta reduzir o autor a um mero nostálgico da morte da narração e da narrativa. Mediante as possibilidades reativas apontadas por Benjamin, como a ausência da palavra compartilhada e o esfacelamento da narrativa, Gagnebin marca a ocorrência de um processo duplo de interiorização no nascente da era moderna - a interiorização psicológica e a interiorização espacial.

No domínio psíquico, os valores individuais substituem as crenças coletivas e "a história do si vai, pouco a pouco, preencher o papel deixado vago pela história comum"(GAGNEBIN, 2011, p.59). Nesse contexto, Benjamin traz o conceito de vivência (Erlebnis) a qual, em oposição à experiência (Erfahrung), conduz as experiências compartilhadas a um novo registro individualizado, anônimo e solitário, materializado em uma arquitetura onde se privilegia o espaço privado como refúgio a um universo externo, frio e hostil (GAGNEBIN, 2011). Tais modificações produziriam uma espécie de fragmentação tanto o sujeito quanto em seu meio social, acentuando uma ruptura entre o público e o privado.

\section{O desmentido social frente ao traumático}

Sandor Ferenczi nasceu na Hungria, fazendo parte da primeira geração de psicanalistas próximos a Freud. Embora sua obra seja ainda pouco difundida entre pesquisadores do trauma social, tomamos de empréstimo a suscinta referência a este autor realizada pela psicanalista húngara Maria Torok: 
acidentes, afecções, pathos. E se fosse nomear a pedra angular sobre a qual volteiam as querelas psicanalíticas, seria a mesma palavra - catástrofe (TOROK, 2000apudGONDAR,2012, p. 194).

Embora Ferenczi tenha falecido prematuramente em 1933, no auge de suas produções clínicas, percebemos a pertinência de seus pensamentos na contemporaneidade. O autor não chegou a vivenciar os conflitos de um mundo polarizado pela Guerra Fria apósa desastrosa Segunda Guerra Mundial, assim como os traumas sociais advindos do Holocausto e das guerras civis posteriores em vários continentes, como foi o caso das ditaduras latino-americanas. Ainda assim, segundo Gondar, o psicanalista húngaro "é considerado o grande pensador do trauma e da catástrofe no campo psicanalítico" (GONDAR, 2015, p.2).

A psicanalista Teresa Pinheiro enfatiza como característica original da teoria do trauma ferencziano "atribuir ao desmentido toda responsabilidade do trauma" (1995, p. 73, grifos da autora) por impossibilitar, desta forma, o processo de introjeção. Ao relacionar a teoria do trauma desenvolvida por Ferenczi em sua maturidade clínica com o início de suas produções, a autora referencia o artigo "Transferência e introjeção", no qual, em sua primeira definição sobre introjeção, Ferenczi ([1909]/1992b) a corresponde ao princípio fundante do aparelho psíquico, a base do começo de tudo, constituinte, portanto, da própria linguagem. Neste sentido, assemelha-se às concepções freudianas acerca do narcisismo primário publicadas cinco anos depois em "Sobre o narcisismo: uma introdução" (FREUD, [1914]/1974).

Posteriormente, ao escrever "O conceito de introjeção" Ferenczi reafirma a introjeção como "a extensão ao mundo externo do interesse, auto-erótico na origem, pela introdução dos objetos exteriores na esfera do ego. Insisti nessa "introdução" para sublinhar que considero todo amor objetal (ou toda transferência) como uma extensão do ego ou introjeção" (FERENCZI, [1912]/1992b, p. 181, grifos do autor).

Foi a partir de 1930 que Ferenczi inicia um processo de distanciamento das concepções de Freud acerca da teoria do trauma, tornando-se seu dissidente. A teoria do trauma em Ferenczi diferiu da proposta freudiana tanto na leitura clínica acerca do trauma quanto na proposta de seu tratamento. Freud concebia o trauma em termos econômicos, ligado a um excesso impactante e não assimilável pelo sujeito pelo tom afetivo excessivamente intenso da experiência (FREUD, [1917]/1976).

Ferenczi ([1934]/1992a) percebia o trauma para além do excesso como evento inicial, considerando também uma gama de complexos relacionais, utilizando como exemplo um caso de referência que traz para a cena familiar o desmentido. Trata-se 
de uma narrativa que envolve três personagens: uma criança, um adulto que abusa sexualmente dela e outro adulto como referência de segurança, a quem a criança endereça seu infortúnio, buscando compreender o que se passou.

Primeiramente, um adulto violenta uma criança - um evento excessivo; no entanto,

(...)não temos ainda todo o complexo construído por Ferenczi já que, para ele, uma violência excessiva não é necessariamente aniquladoraou invalidante. Para que um trauma seja invalidante, é preciso que à experiência de violência física se acrescente outra experiência; ela ocorre quando a criança, sem conseguir dar sentido ao que ocorreu, procura outro adulto na família ou em seu entorno que lhe forneça alguma referência ou explicação sobre o que ela vivenciou (GONDAR, 2015, p.4).

Este adulto eleito pela criança como referência não oferece uma escuta sensível ao seu relato. Negligenciando ou duvidando de seu discurso, além de não acolher o seu sofrimento, agrava a situação ao considerá-lo ser fruto de sua imaginação ou de uma mentira. A esta negação Ferenczi chama de Verleugnung, desmentido, termo que pode também ser compreendido como descrédito ou desautorização (PINHEIRO, 2016).

Essa descrença por parte do interlocutor implica uma falta de elementos afetivos constituintes que possibilitem conferir sentido ao seu sofrimento. Com isso, a criança passa a duvidar do que houve, do que sente e do que percebe como realidade. Portanto, o desmentido não é só uma questão da palavra negligenciada ou negada. São os afetos do sujeito diante de seu próprio sofrimento, assim como ele próprio, que estão sendo desmentidos. Essa conjunção entre a violência do ato e o descrédito da vítima configura, para Ferenczi, o trauma invalidante (GONDAR, 2012). A desorientação psíquica daí advinda prejudica a vítima em seu processamento cognitivo e em sua responsividade física e emocional (LEVY, 2011).

Assim como as diferenças subjetivas dos psicanalistas em questão, a conjuntura sociopolítica do Império Austro-Húngaro também traduzia os conflitos e diferenças que dividiam o território em lados opostos. Enquanto Freud vivia em Viena, na Áustria, onde havia maior desenvolvimento econômico, além de uma supremacia cultural e linguística sobre a Hungria, Ferenczi era membro integrante dos intelectuais húngaros que militavam por sua libertação na cidade de Budapeste. Sua família também compartilhava os ideais de luta e resistência frente aos Habsburgos.

Essas diferenças sociopolíticas também reverberaram na forma com que cada psicanalista desenvolveu a clínica diante das situações traumáticas. Era notório que o 
pai da psicanálise primava pelo reconhecimento científico da clínica que construía, sendo cuidadoso quanto ao rigor metodológico que desenvolvia a partir de sua prática. Em contrapartida, Ferenczi era atento à dimensão sociopolítica de sua época, trazendo-a para sua clínica à medida que percebia processos subjetivos atravessando a vida das pessoas de diversas formas nas relações cotidianas, por vezes com certo constrangimento no que tange a relações de dominação na sociedade, na família e nas instituições de modo geral - assim como com a própria psicanálise.

Vale salientar que a natureza dos questionamentos de Ferenczi em relação à práxis analítica não parece ter partido de abstrações teórico-conceituais. Ao contrário disto, surgiram de forma concreta em seu ambiente clínico, com crianças traumatizadas e sujeitos em sofrimento psíquico diante de uma hipocrisia produzida em sociedade, conferidas pelo choque entre a língua da ternura infantil com a língua da paixão dos adultos (FERENCZI, [1933]/1992a).

Percebemos em Ferenczi um psicanalista que integra a clínica a uma dimensão ético-política pouco compreendida em sua época, porém fundamental para as complexidades do universo contemporâneo. Especializando-se em pacientes traumatizados, vítimas de violência na infância (nem sempre com teor sexual), passou a questionar os métodos clínicos da psicanálise clássica como fria, rígida, distante dos afetos do ponto de vista relacional. "Foi para tratar desses pacientes que Ferenczi produziu conceitos, inovações clínicas e transformações no dispositivo psicanalítico, e não seria ilícito pensar que esse dispositivo apresenta implicações politicas - ou, mais rigorosamente, micropoliticas" (GONDAR, 2015, p. 3).

Neste sentido, Gondar se aproxima das ideias postuladas pelo filósofo francês Gilles Deleuze, ao considerar a indissociabilidade da clínica e da política diante das questões que a psicanálise contemporânea se defronta no âmbito da vida privada, como nos afetos familiares, nas relações amorosas, nas instituições de ensino ou no trabalho, partindo do pressuposto de que o desejo ganha forma e expressão "diante das injunções de assujeitamento" (DELEUZE, 1979 apud GONDAR, 2015, p. 3).

Sendo um psicanalista sensível ao teor político que atravessava a vida de seus pacientes na esfera privada, Ferenczi compreendia 0 entrecruzamento das subjetividades no cotidiano da esfera pública moduladas pela sociedade ocidental, de forma hierarquizada. Desta maneira, passou a questionar a sua própria postura como analista, assumindo seus fracassos diante de situações traumáticas que o método psicanalítico, a seu ver, não conseguiria abarcar de forma integral. 


\section{O testemunho como agente de memória social e política}

Ainda sob os efeitos de uma época em que crimes hediondos vêm se reproduzindo e deixando marcas irreparáveis na sociedade contemporânea - como as duas grandes guerras mundiais, as ditaduras latino-americanas e as guerras civis que ainda acontecem de forma generalizada no mundo, percebe-se como característica do Século XXI a materialização de traumas sociais em uma diversidade de situações de catástrofes e barbárie. Por trauma social, Ortega Martínez (2011) entende os processos pelos quais as comunidades lidam com a construção, elaboração e a resposta a experiências de fraturas sociais graves, percebidas como moralmente injustas, elaboradas não individual, mas coletivamente.

O sociólogo francês Maurice Halbwachs (2003), precursor da concepção clássica da memória coletiva, havia percebido a necessidade de diferenciá-la da memória histórica. Segundo ele, enquanto a primeira traduz uma multiplicidade de aspectos da esfera social por intermédio da oralidade, a segunda restringe-se a um registro discursivo hegemônico produzido pelos representantes do poder oficial, ou seja, pelo próprio Estado. O autor problematiza a artificialidade do conceito de memória histórica como representante de uma coletividade na medida em que busca congelar e eternizar um passado impossível de ser capturado por um discurso unívoco, enquanto que as memórias multifacetadas do social são espontâneas e circulam, se deslocam e transformam-se continuamente ao longo do tempo através do dinamismo de suas relações e de seus afetos.

Contemporâneo da sociologia francesa de Durkheim, Halbwachs considera a memória coletiva como uma faceta dos laços sociais que são estabelecidos e reinventados de forma permanente, através da lembrança. Em uma dimensão mais relacional da sociologia, Halbwachs buscava investigar a memória para além das proposições individualizantes da Psicologia da época, afirmando não existir, na íntegra, uma memória individual. Para ele, a memória é sempre social, pelo simples fato do ato de recordar acontecer através da interação com os outros. Tanto em sua forma factual quanto no sentido da evocação de uma lembrança, colocamo-nos sempre na perspectiva de nossas experiências sociais. A coesão social poderia ser considerada como um ponto de convergência entre os dois sociólogos, pois tanto o conceito de solidariedade em Durkheim como o de memória social em Halbwachs foram concebidos como formas de superação de conflitos. 
$\mathrm{Na}$ abordagem durkheimiana, a ênfase é dada à força quase institucional dessa memória coletiva, à duração, à continuidade e à estabilidade. Assim também Halbwachs, longe de ver nessa memória coletiva uma imposição, uma forma específica de dominação ou violência simbólica, acentua as funções positivas desempenhadas pela memória comum, a saber, de reforçar a coesão social, não pela coerção, mas pela adesão afetiva ao grupo, donde o termo que utiliza de "comunidade afetiva". Na tradição européia do século XIX, em Halbwachs, inclusive, a nação é a forma mais acabada de um grupo, e a memória nacional, a forma mais completa de uma memória coletiva (POLLAK, 1989 , p. 3, grifos do autor).

Michael Pollak, sociólogo polonês que dedicou seus estudos ao pós-guerra, em especial às narrativas dos testemunhos e sobreviventes do Holocausto, parte do pressuposto de que a memória é seletiva por natureza e sofre constantes flutuações e disputas, concebendo elementos constitutivos tanto da memória individual como da memória coletiva. Segundo o autor, a memória individual desenvolve-se por intermédio dos acontecimentos vivenciados pela pessoa, ou seja, presencialmente, enquanto a memória coletiva decorre dos acontecimentos "vividos por tabela", influenciados pela coletividade a qual a pessoa sente pertencer, também se considerando as formas imaginárias de pertencimento (POLLAK, 1992, p. 201).

Pollak (1989) concebe a memória nacional como história oficial, através de narrativas que traduzem um universo hegemônico, interpretadas e influenciadas pela classe dominante de forma intencional e organizada, direcionando de certa forma a memória de um povo, embora também não esteja isenta de disputas e conflitos sociais. Desta forma, o autor salienta um fenômeno recente nas sociedades contemporâneas: as memórias subterrâneas, por meio da insurgência de memórias de grupos minoritários na perspectiva de confronto com a memória oficial.

\footnotetext{
Ao privilegiar a análise dos excluídos, dos marginalizados e das minorias, a história oral ressaltou a importância das memórias subterrâneas que, como parte integrante das culturas minoritárias e dominadas, se opõem à "Memória oficial", no caso a memória nacional. [...] Por outro lado, essas memórias subterrâneas que prosseguem seu trabalho de subversão no silêncio e de maneira quase imperceptível, afloram em momentos de crise em sobressaltos bruscos e exacerbados.A memória entra em disputa. Os objetos de pesquisa são escolhidos de preferência onde existe conflito e competição entre memórias concorrentes (POLLAK, 1989, p. 5).
}

De acordo com Pollak, através das memórias subterrâneas, muda-se o foco da memória clássica, de "coesão social para os conflitos e disputas entre memórias", como nos diz Lifschitz (2014, p. 151).

Segundo Pollak, tais fenômenos emergentes que vêm fomentando memórias 
subterrâneas tornaram-se evidentes em alguns contextos políticos pelo mundo afora, como foi o caso da perestroika na URSS, do apartheid na África do Sul, dos conflitos na Argélia, dentre outros, assim como nas ditaduras latino-americanas.

Para muitos pensadores contemporâneos, o séc. XX é caracterizado por traumas sociais provocados por catástrofes de cunho político, através da violência estatal. Diante de tantos eventos traumáticos que afetam toda a sociedade, Fassin e Rechtman (2007) defendem a ideia de que tais eventos traumáticos emergem dos conflitos políticos do capitalismo do pós-guerra, configurando como nova categoria identitária a condição de vítima.

Nesta conjuntura, abre-se um vasto campo de pesquisas acadêmicas e práticas clínicas inclinadas a buscar compreender o trauma em uma perspectiva sociocultural. Surgem também vários processos sociais reivindicativos com teor reparatório, sejam a partir da noção do estresse pós-traumático contemplados nos compêndios que orientam as nosologias psiquiátricas (como as CID e os DSM), assim como as reivindicações com teor de militância dos direitos humanos, buscando-se alcançar maior visibilidade aos perseguidos políticos através do reconhecimento.

Portanto, de acordo com Fassin e Rechtman (2007), surgem novas modalidades para o campo de atuação acerca do trauma social, a saber - as reparações políticas, o testemunho e a prova. Deste modo, o resgate da memória coletiva dos grupos ou minorias sociais que resistiram às barbáries de guerra tornamse imprescindíveis para se contrapor ao discurso histórico unilateral dos vencedores, que sempre investiram no esquecimento através da invisibilidade e/ou criminalização de sujeitos históricos.

Importante ressaltar que, desde os anos 1970, marcados pelas ditaduras latino-americanas, instituições comprometidas com a clínica psicológica com uma vertente política, assim como organismos atuantes na defesa dos Direitos Humanos, vêm protagonizando um novo campo de trabalho de forma transversal e interdisciplinar, no sentido de oferecer cuidados e maior visibilidade aos testemunhos de vítimas de tortura em crimes de lesa-humanidade perpetradas pelo Estado.

O intuito clínico do analista diante do sofrimento de sujeitos que vivenciaram a tortura ou tiveram seus familiares ou pessoas próximas desaparecidas (supostamente assassinadas) não seria apenas o de um intérprete, mas, também o de testemunho. Neste sentido, o encontro entre o analista e seu analisando pode ser compreendido como um encontro de testemunhas, sem possibilidadede de cifrar o que ainda não 
pode ser cifrado. Seria como fazer psicanálise "ao revés", em busca de um processo terapêutico que inclua alguma possibilidade de decifrar o indizível e irrepresentável do trauma (INSUA, 2013, p. 28). E se existe alguma possibilidade deste processo acontecer, poderíamos apontar para a relação entre vulneráveis em direção a relações humanas mais horizontais, retomando a concepção ferencziana de uma clínica permeada por afetos entre analista e analisando - neste caso, cúmplices - através do testemunho como um processo subjetivo a ser recriado.

A rememoração dos momentos de tortura física e psicológica é sempre muito dolorosa, conforme o relato da testemunha, Eliete Ferrer, ilustrado por Moisés Rodrigues da Silva: "Quando a gente fala, o assunto duro, pontudo, que machuca como um ouriço vai-se polindo e todo mundo consegue segurá-lo" (WONDRACEK, 2014, p. 107). A beleza desta metáfora consiste em redimensionar a relação clínica entre testemunhos como uma arte especial - a de polir ouriços pontiagudos.

O psicanalista brasileiro Helio Pellegrino, ao acompanhar em sua clínica os relatos das vítimas da ditadura brasileira, observava a ocorrência de uma ruptura radical entre o corpo e a mente diante da tortura, fazendo com que o próprio corpo do torturado se tornasse seu maior inimigo, ao tentar extinguir a dor.

A tortura, por exemplo: ela é um crime essencial, substantivo, ontológico. Ataca - e corrói - o fundamento da pessoa humana. A tortura visa à produção diabólica de um discurso que é o avesso da liberdade. Ela vira o torturado pelo avesso, na busca de uma confissão que o destrói, envenenando as fontes de sua vida carnal e de seus valores espirituais. A tortura - corrupção absoluta - serve ao mal e à morte. A dignidade da vida, também absoluta, exige que em nenhum momento nos esqueçamos da tortura, sua negação mais aviltante (PELLEGRINO, 1982, p. 11).

Em seu escrito Gênero, militância, tortura, Cecília Coimbra faz a transcrição de um trecho do depoimentode um ex-preso político que testemunhou a radicalidade da tortura, preservando o seu anonimato:

\begin{abstract}
Infelizmente, setores importantes da sociedade não têm a menor ideia de que significa a tortura.[...] Tortura é uma das práticas mais perversas: é a submissão do sujeito ao lhe ser imposta a certeza da morte. Não é uma morte qualquer: é a morte com sofrimento, a morte com muita agonia, é a morte que ocorre bem devagar, porque o desespero deve ser potencializado. O choque elétrico rasga, como golpes, as entranhas do indivíduo, e o coração parece que vai explodir. O afogamento mescla de água e ar, é a consciência da parada cardíaca, a dor dos pulmões encharcando. O pau de arara, o cigarro aceso queimando a pele e a carne. Várias horas seguidas e em várias horas do dia, da noite, da madrugada (COIMBRA, 2011, p. 47).
\end{abstract}

Como foi ilustrado neste depoimento de uma vítima do regime ditatorial, a falta 
de responsabilização do Estado brasileiro diante dessas graves violações contribuiu para o desconhecimento histórico da própria sociedade. Desta forma, o sofrimento inflingido às vítimas deste período produziu uma dupla violação, pois, além do trauma sofrido pelo sujeito em seu corpo e em sua alma, a negação do ocorrido promoveu uma ferida que se alastrou no corpo social das gerações posteriores, à medida que impossibilitou se estancar a dor diante da impunidade dos torturadores e do silenciamento imposto à sociedade.

\section{Reparação simbólica aos afetados pela ditadura}

A partir da diversidade de pesquisas sócio-históricas acerca do testemunho, desde o Holocausto, consideramos a necessidade de investigação do testemunho de pessoas que vivenciaram situações traumáticas de tortura nas ditaduras latinoamericanas, emparticular, no contexto brasileiro. Intentando uma interlocução com psicanalistas que vêm atuando em dispositivos clínicos dedicados a uma práxis sensível à escuta de testemunhas sobreviventes de crimes da ditadura brasileira, nosperguntamos qual seria o teor do trabalho psicanalítico comprometido com o trauma individual em interface com o trauma social, diante da radicalidade do sofrimento psíquico e corporal produzidos pela torturae abafados pela censura ditatorial? Há possibilidades de reparação? E qual sentido pode ser atribuído à reparação?

Em relação à complexidade inerente a questões da reparação de um trauma, além de seu percurso da esfera privada à esfera pública envolvendo o esquecimento e fragmentação de memórias, apontamos para algumas possibilidades de reparação psíquica com viés político em algumas experiências pioneiras no Brasil - como resistência à impunidade. 
De acordo com a psicanalista Vera Vital Brasil, a experiência clínica de afetados diretos e indiretos da violência de Estado nos tempos da ditadura, assim como nos dias atuais, traduzuma violência institucionalizada por meio de aparatos policiais que ainda praticam perseguições, torturas, assassinatos e desaparecimentos, legitimados por políticas de segurança nacional. Como ex-presa política da ditadura brasileira, a psicóloga possui uma trajetória de militância, sendo uma das fundadoras do Grupo Tortura Nunca Mais (GTNM) - movimento organizado por familiares de desaparecidos e de ex-presos políticos - e coordenadora da primeira edição do Projeto Clínicas do Testemunho-RJ.

O Projeto Clínicas do Testemunho foi concebido para integrar as políticas reparatórias do Ministério da Justiça (BRASIL, 2012) através da Comissão da Anistia, inaugurando uma nova vertente de atuação: a reparação psicossocial aos afetados diretos e indiretos da ditadura. A reparação psicossocial passou a integrar o quinto pilar da justiça de transição do país, sendo a busca da verdade dos fatos, a garantia de memória das vítimas, a punição dos agentes criminosos do Estado e a reforma das instituições perpetradoras de violações parte das perspectivas a serem conquistadas.

Dentre esses pilares, podemos questionar certa contradição ao pensarmos em uma estratégia política de alguns segmentos do próprio Estado brasileiro, configurando-se um campo de disputa e de forças, visto que nem todas as ações vêm se dando de forma integral, como é o caso da negação ao direito à justiça através da punição de seus agentes. Diante do exposto, podemos nos perguntar, afinal, qual a justificativa que possibilita a necessidade de uma reparação psicológica assumida pelo Estado aos afetados diretos e indiretos das violações ocorridas no passado?

Segundo o coordenador da Comissão da Anistia, Paulo Abrão, ao apresentar a proposta do Projeto Piloto Clínicas do Testemunho, o fato dos danos psicológicos às vitimas da ditadura ter sido causado pelo próprio Estado já seria uma justificativa plausível para a construção desta política pública. Sendo assim, dimensiona mais dois pontos que especificam o caráter do Estado como agente violador. Como primeiro argumento, quando o terror é perpetrado pelo próprio Estado, é a sociedade que fica prejudicada, pois,

quando o agente regulador dos vínculos sociais põe-se na ilegalidade, é a própria substancia normativa da sociedade que se dissipa. [...]

Em segundo lugar, é importante notar que existe uma diferença simbólica essencial quando uma ação de reparação a crimes de lesa-humanidade é oferecida não somente por grupos e entidades não governamentais, mas pelo poder público. Tanto em termos de valor histórico, para a sociedade, quanto 
em termos de valor subjetivo, para o paciente, somente as políticas públicas de reparação podem carregar o símbolo da admissão, pelo Estado, do crime que ele mesmo perpetrou. Para a vítima, o valor desse gesto e inestimável: assim como não existe luto sem reconhecimento da morte, não há reparação possível sem o reconhecimento oficial do crime (ABRÃO, 2014, p. 16).

Importante ressaltar os antecedentes históricos que possibilitaram 0 amadurecimento desta nova proposta de reparação política através de dispositivos clínicos oriundos de alguns movimentos sociais que resistiam às ditaduras - em especial, de familiares das vítimas da violência de Estado que lutavam pela anistia no Brasil e em países vizinhos da América Latina.

Logo após o término da ditadura, militantes de direitos humanos que resistiram ao regime criaram, em 1985, o Grupo Tortura Nunca Mais do Rio de Janeiro. Em 1991, o GTNM/RJ foi pioneiro na criação de um dispositivo clínico-grupal, com o intuito de oferecer cuidados clínicos aos afetados pela violência de Estado da ditadura, extensivos aos familiares e aos afetados pela violência contemporânea.

Segundo Vera Vital Brasil (2010), tal iniciativa foi compartilhada por outros atores sociais, como profissionais de saúde de vários segmentos no Brasil e em outros países da América Latina. Foram nove anos de experiência que, segundo a psicóloga, possibilitaram o amadurecimento e a sistematização deste trabalho, estendendo-se a outras redes sociais, com programas socioeducativos em várias cidades brasileiras. Em outros países da América Latina também funcionam programas de reparação integrados às políticas públicas, favorecendo o intercâmbio destas experiências, assim como o fortalecimento e apoio desses grupos de resistência frente ao recrudescimento e atraso do governo brasileiro em seu processo de justiça.

Partindo-se do entendimento de que o Estado tem a obrigação de reparar os danos cometidos por seus agentes, a iniciativa clínico-grupal do GTNM transformouse, em 2010, num grupo autônomo, a Equipe Clínico-Política - Projetos Terapêuticos/RJ, tendo como bandeira de luta cobrar do Estado brasileiro a efetivação de uma política pública reparatória de cunho psicossocial (VITAL BRASIL, 2010). A conjuntura política do país era pertinente, visto que algumas brechas se abriam como possibilidades de avanços para alguns organismos de direitos humanos e à democracia. O processo de construção de projetos de políticas reparatórias através da Comissão da Anistia, assim como a implementação do Plano Nacional de Direitos Humanos (PNDH-3), com a participação da sociedade civil, seriam alguns exemplos.

Porém, até 2013, o processo de reparação estava atrelado apenas a dispositivos de ordem moral e de compensação econômica. Foi com a mobilização da 
sociedade civil, através do Projeto Caravanas da Anistia e do Projeto Marcas da Memória, que se pôde pensar em avançar nas discussões de reparação psicológica, visto que nos testemunhos públicos as marcas deixadas pelos anos de silenciamento e de tortura tornaram-se evidentes.

\section{Considerações finais}

A Comissão da Anistia iniciou o processo de pedido de desculpas por parte do governo brasileiro aos afetados pela ditadura civil-militar através do Projeto Caravanas Itinerantes, inaugurando oficialmente, e de forma pública,em vários estados do país, a prática de construção da Memória e da Verdade. Esta prática se dá por meio dos testemunhos daqueles que reivindicam o direito ao reconhecimento dos mortos $\mathrm{e}$ desaparecidos políticos, bem como à reparação pelos danos advindos de torturas e perseguições.

Alguns profissionais envolvidos na escuta clínica dos afetados pela violência de Estado vêm apontando que o investimento político nesta clínica não pode ser concluído sem o investimento de uma política pública de reparação integral, ou seja, do "reconhecimento público dos danos causados pelo Estado e criadas ações e políticas voltadas para uma reparação integral dos afetados" (VITAL BRASIL, 2010, p. 272).

Porém, na atual conjuntura brasileira, vivemos uma crise política de retrocessos do processo democrático, colocando em xeque os avanços conquistados recentemente com as políticas reparatórias, após muitas lutas travadas por movimentos sociais no país, em especial pelos familiares dos desaparecidos e/ou perseguidos políticos.

Estamos novamente em confronto com o desmentido na esfera política, com atravessamentos de jogos de poder interferindo no campo das relações sociais através da impunidade e das disputas por memória.

Diante do exposto, potencializar o testemunho como acontecimento em uma sociedade vulnerável a traumas e esquecimentos nos convoca a uma dimensão política da clínica enquanto memória dos grupos ainda negligenciados pela história oficial. Apesar dos retrocessos concernentes à manutenção dos processos reparatórios por parte do Estado brasileiro, percebemos que as narrativas dos testemunhos ainda resistem nos dispositivos clínico-políticos, e em outras modalidades de expressãomaterializadas em acervos audiovisuais, na literatura, no teatro e nas 
artes plásticas,potencializando a transmissão da memória coletiva deste trágico período da história brasileira.

\section{Referências:}

ABRÃO, Paulo. Apresentação. In: SIGMUND FREUD ASSOCIAÇÃO PSICANALÍTICA. Clínicas do testemunho: reparação psíquica e construção de memórias.Porto Alegre: Criação Humana, 2014.p.15-21.

BENJAMIN, Walter.Experiência e pobreza [1933]. In: . Magia e Técnica, Arte e Política - Obras Escolhidas, v.1. 7. ed. São Paulo: Brasiliense, 1994. p. 114-119.

BENJAMIN, Walter. O narrador: considerações sobre a obra de Nikolai Leskov [1936]. In: Magia e Técnica, Arte e Política - Obras Escolhidas, v.1. 7. ed. São Paulo: Brasiliense, 1994.p. 197-221.

BRASIL. Ministério da Justiça/Comissão de Anistia. Edital da I Chamada Pública do Projeto Clínicas do Testemunho da Comissão de Anistia. Brasília, 2012. Disponível em:<http://www.sedes.org.br/Departamentos/Psicanalise/boletim/edicao24/edital_clinic as_do_testemunho.pdf>. Acesso em: 15 jul. 2017.

COIMBRA, Cecília. Gênero, militância, tortura. In: FERRER, Eliete (Org.). 68 A geração que queria mudar o mundo: relatos. Brasília: Ministério da Justiça/ Comissão de Anistia, 2011.p. 39-48.

DELEUZE, Gilles. Quatro proposições a respeito da Psicanálise. In: KATZ, Chaim S. (Org.) Psicanálise, poder e desejo. Rio de Janeiro: IBRAPSI, 1979.p. 65-72.

FASSIN, Didier; RECHTMAN, Richard. L'Empire du traumatisme: enquête sur la condition de victime. Paris: Flammarion, 2007.

FERENCZI, Sándor. Confusão de línguas entre os adultos e a criança [1933]. In: Obras Completas, v. IV. Rio de Janeiro: Martins Fontes, 1992a. p. 97-106.

FERENCZI, Sándor. Reflexões sobre o trauma [1934]. In: Obras Completas, v. IV. Rio de Janeiro: Martins Fontes, 1992a.p. 109-117.

FERENCZI, Sándor. O conceito de introjeção [1912]. In: Obras Completas, v. I. Rio de Janeiro: Martins Fontes, 1992b.p. 181-183.

FERENCZI, Sándor. Transferência e introjeção [1909]. In: Obras Completas, v. I. Rio de Janeiro: Martins Fontes, 1992b.p.77-108.

FREUD, Sigmund. Conferências introdutórias sobre psicanálise. Conferência XVIII Fixação em Traumas - O inconsciente. [1917]. In: Edição Standard Brasileira das Obras Psicológicas Completas de Sigmund Freud.v. XVI. Rio de Janeiro: Imago, 1976.p.323-336.

FREUD, Sigmund. Sobreo narcisismo: uma introdução [1914]. In: Edição Standard Brasileira das Obras Psicológicas Completas de Sigmund Freud, v. XIV.Rio de Janeiro: Imago, 1974.p. 89-119. 
GAGNEBIN, Jeanne Marie. História e narração em Walter Benjamin. São Paulo: Perspectiva, 2011.

GONDAR, Jô. Trauma social e políticas de reconhecimento: as contribuições de Sándor Ferenczi. Conferência apresentada na passagem a professor titular da autora na UNIRIO em 07 de jul. 2015.

GONDAR, Jô. Ferenczi como pensador político. Cadernos de Psicanálise, CPRJ, Rio de Janeiro, v. 34, n. 27, p. 193-210, julh-dez. 2012.

HALBWACHS, Maurice. A memória coletiva. São Paulo: Centauro, 2003.

INSUA, Gabriela. (Org.). Lo indecible: clínica con lo traumático. Buenos Aires: Letra Viva/Centro Dos, 2013.

LEVY, Sofia D. Trauma e desintegração psíquica na contemporaneidade. In: FARIAS, Francisco R. (Org.) Apontamentos em memória social. Rio de Janeiro: Contracapa, 2011. p. 75-92.

LIFSCHITZ, Javier Alejandro. Os agenciamentos da memória política na AméricaLatina. Revista Brasileira de Ciências Sociais (Impresso), São Paulo, v. 29, p. 145-158, 2014.

ORTEGA MARTÍNEZ, Francisco A. (ed.) Trauma, cultura e historia: reflexiones interdisciplinarias para El nuevo milenio. Bogota: Universidad Nacional de Colombia. Facultad de Ciencias Humanas. Centro de Estudos Sociales, 2011.

PELLEGRINO, Helio. A tortura política. Folha de São Paulo, p.11.São Paulo, 05 de jun. 1982.

PINHEIRO, Teresa. Ferenczi. São Paulo: Casa do Psicólogo, 2016. (Coleção Clínica Psicanalítica / dirigida por Flavio Carvalho Ferraz).

PINHEIRO, Teresa. Ferenczi: do grito à palavra. Rio de Janeiro: Jorge Zahar; Rio de Janeiro: UFRJ, 1995.

POLLAK, Michael. Memória e identidade social. Estudos Históricos, v. 5, n. 10, p. 200-212, 1992.

POLLAK, Michael. Memória, esquecimento, silêncio. Rio de Janeiro, Estudos Históricos, v. 2, n. 3, p. 3- 15, 1989.

TOROK, Maria. Catastrophes: Katasztrófak. Le Coq-Héron, Paris, n. 159, p. 37-38, 2000. (Número especial).

WONDRACEK, Karin Hellen. Sobre a arte de polir ouriços: psicanálise e história na clínica dos afetados pela violência de Estado.In: SIGMUND FREUD ASSOCIAÇÃO PSICANALÍTICA. Clínicas do testemunho: reparação psíquica e construção de memórias.Porto Alegre: Criação Humana, 2014.p. 15-21. 
VITAL BRASIL, Vera. Dano e Reparação: construindo caminhos para enfrentar a tortura. COORDENAÇÃO GERAL DE COMBATE À TORTURA (org.). Tortura. p.254279. Brasília: Secretaria de Direitos Humanos da Presidência da República, 2010.Disponível em: <http://www.dhnet.org.br/dados/livros/dh/livro_sdh_tortura.pdf >. Acesso em: 10 out. 2014.

O presente trabalho foi realizado com o apoio da CAPES 